\title{
Adapting Supportive Care Guidelines from High- income Countries; Real World Data on Approach to Neutropenic Sepsis in Haemato-Oncology Patients in Sri Lanka
}

Saman Hewamana ( $\nabla$ samanhewamana@live.co.uk)

Lanka Hospital, Colombo, Sri Lanka https://orcid.org/0000-0002-5439-8398

Thurairajah Skandarajah

National Cancer Institute, Colombo, Sri Lanka

Chathuri Jayasinghe

Department of Statistics, University of Sri Jayawardenapura,Colombo, Sri Lanka

\section{Samadhi Deshapriya}

Clinical Haematology Unit, Lanka Hospital, Colombo, Sri Lanka

\section{Dhananjani Senarathna}

Clinical Haematology Unit, Lanka Hospital, Colombo, Sri Lanka

\section{Dilip Gayashan}

Lanka Hospital Diagnostics, Colombo, Sri Lanka

\section{Natasha Peiris}

Asiri Surgical Hospital, Colombo, Sri Lanka

\section{Eranga Perera}

Asiri Surgical Hospital, Colombo, Sri Lanka

\section{Mahesh Harischandra}

Lanka Hospital, Colombo, Sri Lanka

\section{Surjit Somiah}

Lanka Hospital, Colombo, Sri Lanka

Nihal Munasinghe

Lanka Hospital, Colombo, Sri Lanka

\section{Sangeetha Hewawasam}

Lanka Hospital, Colombo, Sri Lanka

\section{Gehan Arseculeratne}

Lanka Hospital, Colombo, Sri Lanka

Rohini Wadanamby

Lanka Hospital Diagnostics, Colombo, Sri Lanka

\section{Geethani Galagoda}


Jayantha Balawardena

General Sir John Kotelawala Defence University Faculty of Medicine

\section{Research Article}

Keywords: Blood cancer, Haemato-Oncology, Sepsis, Neutropenia, Chemotherapy, GCSF

Posted Date: July 15th, 2021

DOl: https://doi.org/10.21203/rs.3.rs-626896/v1

License: (c) (1) This work is licensed under a Creative Commons Attribution 4.0 International License. Read Full License 


\section{Abstract}

\section{Background}

Sepsis is the main cause of non-relapse mortality and there are no published data on applicability of supportive care protocols from high-income countries in Sri Lanka. The aim of the study was to investigate management and mortality of neutropenic episodes among Haemato-Oncology patients.

\section{Methods}

We analysed retrospectively clinical characteristics, management, morbidity and mortality of neutropenic adult Haemato-Oncology patients from 01.01.2019 to 31.12.2019.

Results

A total of 169 neutropenic episodes were identified; 115 (68\%) of such episodes were related to chemotherapy. Acute leukaemia, Lymphoproliferative disorders and Plasma cell disorders accounted for $23 \%, 69 \%$ and $8 \%$ of patients respectively. The median age of patients who had sepsis was 56 while that of those who had no sepsis was 53 (p-value 0.49). Median time to neutropenia was 9 days for those in the sepsis group compared to 8 days in the group that had no sepsis (0.64). Median neutrophil count in the group who had sepsis was 0.06 while it was 0.69 in the group that had no sepsis ( $p$-value 0.000). Median time to commencement of antibiotics was 20 minutes. There were no deaths in the group of chemotherapy induced neutropenic sepsis.

Conclusion

This is the only documented study relating to outcome and successful applicability of western supportive care protocols to Sri Lankan patients with neutropenia. In this study we have shown that survival data comparable to developed countries can be achieved in the setting of limited resources with service development, following guidelines and staff training.

\section{Highlights}

We reviewed the outcome of neutropenic episodes among Haemato-Oncology patients

Neutropenic episodes result from disease and / or treatment

We used modified guidelines from high-income countries for prevention and treatment of sepsis

Ongoing surveillance is used to guide antibiotic therapy

Western guidelines in combination with local know how are highly effective in prevention and treatment of sepsis 
Continuous monitoring of care is of paramount importance in maintaining the quality of treatment

\section{Introduction}

Sepsis is a common, dreaded and costly complication in cancer patients (1). Haemato-Oncology patients have a higher risk of acquiring infections and has been known for decades as the main cause of death (2). Infections can progress rapidly with very high mortality due to impaired immune and myeloid systems. Haemato-Oncology patients with fever are known to be at an increased risk of bloodstream infections irrespective of the neutrophil count. Due to complexity of haematological malignancies, complications due to treatment, comorbidities associated with increasing age, these patients require multidisciplinary strategies and care from staff experienced in blood cancer management.

There is a distinct difference in the cancer survival between low- and high-income countries and complications related to infections contribute significantly towards higher morbidity and mortality in low income countries (3).

Sri Lanka is a developing country with a diverse health care system. Unlike in the UK, hospitals in Sri Lanka are likely to have different approaches in managing the same disease and also significant heterogeneity exists with regard to diagnostic and treatment facilities, access to trained personnel and supportive care. We established the Lanka Hospital Blood Cancer Centre (LHBCC) in a self-financing hospital in Sri Lanka in collaboration with colleagues from government subsidised hospitals with designated space, staff and a strategy to treat blood cancers using treatment and supportive care protocols from the United Kingdom (UK). However, there is no published data on applicability of supportive care protocols from high-income countries in neutropenic sepsis in Haemato-Oncology patients in Sri Lanka. We used modified guidelines from high-income countries to prevent and treat neutropenic episodes in blood cancer patients in Sri Lanka. We have previously published data on the successful application of British treatment protocols in acute myeloid leukaemia (4), in Hodgkin Lymphoma (5) and other haematological malignancies (manuscript in preparation).

The aim of the present study was to investigate clinical characteristics, management, mortality and morbidity of neutropenic episodes among Haemato-Oncology patients in a low-income country.

\section{Materials And Methods}

The study was considered as a quality improvement activity and approval was obtained from the Lanka Hospitals medical research and the ethics committee.

We retrospectively analysed clinical characteristics, management, morbidity and mortality of neutropenic Haemato-Oncology patients who presented to LHBCC from 01.01.2019 to 31.12.2019. Neutropenia and sepsis are previously defined in guidelines $(6,7)$. We used the criterion of neutrophil count of $1 \times 10^{9} / \mathrm{L}$ or lower or likely to reach below $1 \times 10^{9} / \mathrm{L}$ due to disease or treatment as neutropenia. Neutropenic sepsis is defined as patients having temperature of $38^{\circ} \mathrm{C}$ persistent for 1 hour or more or other signs or symptoms 
consistent with clinically significant sepsis in a patient with neutrophil count of $1 \times 10^{9} / \mathrm{L}$ or lower. We analysed age, gender, cause for neutropenia (disease or / and type of chemotherapy), time of chemotherapy to neutropenia (CTN), time from neutropenia to sepsis (NTS), maximum CRP, minimum neutrophil count $(N)$, minimum platelet count $(P)$, minimum haemoglobin $(H)$, time to antibiotic administration from the entry to the ward or time of sepsis (TTA), type of antibiotic, culture results, duration of antibiotic use (A), duration of growth factor use (G), duration of hospital stay (IP), duration of neutropenia (DN) and outcome. Mann Whitney $U$ test and Kruskal Wallis test were used in the statistical analysis.

\section{Results}

A total of 169 neutropenic episodes were identified; $115(68 \%)$ of such neutropenic episodes were related to chemotherapy while 54 (32\%) episodes were related to disease. There were 43 episodes of chemotherapy induced neutropenic sepsis (CINS) while 72 episodes had chemotherapy induced neutropenia (CIN) but were not septic. In addition there were 9 episodes of disease induced neutropenic sepsis (DINS) while 45 had disease induced neutropenia (DIN) but were not septic. There were 84 admissions; 52 (62\%) episodes were septic and 32 (38\%) episodes admitted due to other reasons. Fifteen percent of patients had only one episode of neutropenic sepsis during the study period while $85 \%$ had more than one episode of neutropenic sepsis (Table 1A and Fig. 1).

All patients had underlying haematological malignancy. Acute leukaemia / myelodysplastic syndrome, Lymphoproliferative Disorders (LPD) and Plasma Cell Disorders (PCD) accounted for $23 \%, 69 \%$ and $8 \%$ of patients respectively in the group neutropenia related to chemotherapy. In this group, the majority of patients were males $54 \%$ (Fig. 1).

The median age of patients who had sepsis was 56 while that of those who had no sepsis was 53 (pvalue 0.49 ). Median time to neutropenia was 9 days for those in the sepsis group compared to 8 days in the group that had no sepsis (0.64). Median time to sepsis from neutropenia was one day (Table 1B and Fig. 2).

Median neutrophil count in the group who had sepsis was 0.06 while it was 0.69 in the group that had no sepsis ( $p$-value 0.000 ). There was no difference between the haemoglobin, platelet count or duration of neutropenia in the group who had sepsis compared to patients without sepsis (Table 1B and Fig. 3).

Median duration of antibiotic therapy was 4 days while that of CSF therapy was 3 days. Median duration of neutropenia was 3 days and the median hospital stay was 5 days. There was no difference in the CRP, median duration of antibiotic usage, CRP, CSF usage, duration of neutropenia and hospital stay in CINS group compared to DINS group (Table 1B and Fig. 4). Median time to commencement of antibiotics was 20 minutes in both groups, CINS and DINS. There is no difference between the duration taken to commence antibiotics in the week ends compared to commencement on week days (0.48) (Table 1C)

There were no deaths in the CINS but there were 2 deaths in the DINS group. 
Combination of Piperacillin/Tazobactam (4.5 $\mathrm{g} \times$ QID) and Amikacin $(7.5 \mathrm{mg} / \mathrm{kg}$ BID) was the preferred first line empirical treatment in most cases of neutropenic sepsis (40/43). 4 were changed to Carbapenem and 8 were treated with Vancomycin in addition. 3 episodes needed intensive care admission.

Two, two, three and one had positive blood culture, sputum culture, urine culture and ICD culture respectively (Table $2 \mathrm{~A}$ and $2 \mathrm{~B}$ ).

\section{Discussion}

Developing countries lack necessary knowledge, medical practitioners, infrastructure, quality medications and finances which contribute to a shortage of accessible healthcare. There are no standard local protocols, guidelines or guidelines suited for low -income countries resulting in variability in practice and inferior patient out-come.

Sepsis is a major cause of non-relapsed mortality in patients with haematological cancers and has been shown to have 3 -fold higher incidence of sepsis compared to general oncology patients $(8,9)$. Furthermore the average cost of hospitalisation due to neutropenic sepsis in patients with haematological malignancies is higher than in patients with solid tumours (10). It is a well recognised complication of chemotherapy and various measures were implemented to prevent this $(11,12)$.

Sri Lanka is a low-income country with heterogenous health care system. There are no local guidelines on prevention and treatment of neutropenia in Haemato-Oncology patients. Although there are international guidelines with recommendations, decision making in clinical practice is a challenge due to diverse population with varying comorbidities and health care facilities. Furthermore, there are no statistics or published data on response, survival or treatment related mortality in blood cancer patients in Sri Lanka.

Patients receiving chemotherapy for hematological malignancies have prolonged neutropenia and most patients experience at least one episode of neutropenic sepsis. Neshe $L$ et al, showed bacterial infections generally occur during early stage of neutropenia (7 to 10 days) (13). In line with published guidelines, eighty five percent of patients in our cohort had more than one episode of sepsis while median time to neutropenia from chemotherapy was 9 days while onset of neutropenia to sepsis was 1 day.

Weyker $\mathrm{D}$ et al., showed the risk of febrile neutropenia during the chemotherapy regimen course was $16.8 \%$ (14). They analysed solid cancers and Non-Hodgkin Lymphoma (NHL). Thirty six percent of patient episodes with $\mathrm{NHL}$ in our cohort had neutropenic sepsis. In addition, the mean hospital stay in their study was 8.4 days. Comparatively, hospital stay in our study was 5 days while mean duration of neutropenia was 3 days in our cohort. However direct comparison was not possible due to heterogeneity of the patient population chosen to study.

Forty one percent of episodes of neutropenia in patients with acute leukaemia in our cohort had neutropenic sepsis compared to $35-48 \%$ in Acute Myeloid Leukaemia (AML) and 13-30\% Acute 
Lymphoblastic Leukaemia (ALL) reported by others (15). However, it is not possible to differentiate the contribution by chemotherapy and disease towards neutropenia, particularly during the first cycle of chemotherapy in acute leukaemia.

Severe neutropenia (absolute neutrophil count of less than $0.1 \times 10^{9} / \mathrm{L}$ ) associated with increased risk of severe infections $(16,17)$. However, others have not seen a significant association between neutrophil count and severe infections (18). Three percent of episodes in this study in the group with chemotherapy related neutropenia had neutrophil count of less than $0.1 \times 10^{9} / \mathrm{L}$. There was a significant difference in the neutrophil count in the CINS group compared to CIN in this study. In addition, we could see a significant difference in hospital admission in the group with severe neutropenia.

Prevention as well as appropriate treatment of neutropenia and neutropenic sepsis are of great importance to maintain dose intensity and continuation of treatment according to schedules. In addition, there are medical, psychological, and financial benefits of staying home (19). It has been shown that inpatient management of neutropenic complications of myelosuppressive chemotherapy cost more than the cost of chemotherapy (20). Prophylactic antibiotics, neutropenic diet and growth factors are used to prevent patients progress to neutropenic sepsis as advised by guidelines from high-income countries (21, 22). However data from clinical trials may not be representative of real-world scenarios and may be not applicable to wider population (23).

We used Ciprofloxacin prophylaxis in all patients when the neutrophil count was below $1 \times 10^{9} / \mathrm{L}$. We were aware that that the risk of gram-negative blood stream infections with quinolone resistance is on the rise and this may be due to higher ciprofloxacin usage in haematology (24). However we considered all patients in LHBCC as high risk due to heterogenous nature in health care facilities available, uncertainty about out-come due to lack of published data, diverse socio-economic status. In addition substantial financial implications due to admissions to a self-financing hospital in Sri Lanka also a factor considered in implementing stringent preventive measures.

Nucci $\mathrm{M}$ et al, showed that Itraconazole prophylaxis reduces the frequency of systemic fungal infections and use of empirical amphotericin B in a double-blind, randomised, placebo-controlled study (25). In line with their findings we had no proven fungal infections and used amphotericin B on no patients during the study period.

Use of Colony Stimulating Factors (CSF) is recommended when the risk of CINS is $20 \%$ or greater but there is a variability in the start time and duration of CSF (23). We used CSF in all patients with nonmyeloid malignancies with CIN. Wider use of CSF in our centre is not in line with and may be inappropriate according to studies and guidelines from high-income countries. However we believe 'appropriateness' should be assed according to cost effectiveness, expertise and facilities available locally. Also similar data is reported in the real-world practice by others (26) and National Comprehensive Cancer Network (NCCN) guidelines advocate wider use of colony-stimulating factor (27). 
Fresh fruit and vegetables contain gram negative bacilli that can cause life threatening infections (28, 29). However subsequent studies have documented that neutropenic diet given in the belief that it can prevent infections has no effect (30). We allowed only well-cooked food in neutropenic patients in LHBCC. Once again, it is questionable how applicable studies done in high-income countries are in the local setting where differences exist between sanitary practices including disposal of human waste and access to safe drinking water.

Gram-negative coverage in neutropenic sepsis has evolved from beta-lactam plus aminoglycoside to single agent broad spectrums such as Cefepime, Piperacillin-Tazobactam and Carbapenems (31). However the applicability of recommendations from high-income countries in the local setting is questionable. We used nurse-led first dose with dual anti-gram-negative antibiotic treatment policy in suspected or proven neutropenic sepsis. We used Piperacillin-Tazobactam and aminoglycoside combination as preferred empirical antibiotic regimen. Our policy to offer dual gram-negative cover is mainly driven by availability of facilities. We did not have specialised trainees but patient care was covered by generalists. Cost of treatment in intensive care is substantial in self-financed hospitals and bed availability in the government subsidised centres is limited. In a country with heterogenous heath care system and sparse resources, we considered it is safer to start dual-antibiotic therapy and change over to single agent or oral therapy once patients were stable.

Guarana et al., 2019 reported shock or early death was mainly due to gram-negative infections but was not associated with gram-positive bacteremia; catheter-related, skin, or soft tissue infection; or inadequate gram-positive coverage (32). Despite stringent preventive measures and emphatical use of antibiotics neutropenic sepsis carries a high mortality which can range from 2-21\% (33) and is higher in adults compared to children (34). Ghosh S et al, has shown a mortality rate of $19.5 \%$ in an Indian study running over one year (35). They have used single-agent cefepime or piperacillin-tazobactam/tigecycline combination as empirical agents. Thirty seven percent of neutropenic episodes in our cohort ended up as in-patients due to sepsis. There were 3 deaths during the study period and two were related to disease related neutropenic sepsis (2/52 episodes) and one non-neutropenic sepsis (1/16 episodes). However no deaths were reported due to post chemotherapy sepsis during the study period.

It has previously been shown the effect of giving antibiotics within an hour in reducing morbidity and mortality in haematological cancers. Rosa $\mathrm{R}$ et al, showed time to antibiotic administration is independently associated with 28-day mortality (36). They have shown starting antibiotics within 30 minutes has a lowest mortality compared to 31 to 60-minute group and each increase in $1 \mathrm{~h}$ has increased the 28 -day mortality by $18 \%$. We had a median time to antibiotics (TTA) of 20 minutes which was within the acceptable range compared to other studies. Ali N., et al., published a study in 2015 about the compliance of 1 hour for TSA (37). They had a median TTA of 45 minutes (range \pm SD: 10 minutes to 6 hours \pm 1 hour 10 minutes). There were long delays particularly over week ends. Our data did not show a significant difference over week -ends or out-side standard working hours ( $p$-value 0.78). We had an admission policy where patients were admitted directly to the Haemato-Oncology ward, by-passing the busy multi-disciplinary single emergency unit of the hospital. A stock of antibiotics was kept on the ward 
and nurses were trained to immediately treat with empirical antibiotics for suspected or proven neutropenic sepsis even before medical review over the phone advice.

Median antibiotic days and median hospital stay were 4 and 5 days respectively in CINS in LHBCC. We continued antibiotics till the neutrophil count was above 1 in CINS but stopped it once sepsis settles in DINS. Median duration of neutropenia was 3 days in CINS and 2.5 days in CIN group. Several studies have shown that intravenous antibiotics can be stopped before neutrophil count recovers above 1(38, 39). Social circumstances in Sri Lanka are different to those in high-income countries and the cost of prolonged treatment self-financing hospital is substantial. Guidelines from high-income countries does not take facilities, expertise, epidemiology of organisms or financial impact of treatment in to account. We were guided by Western guidelines but with appropriate changes taking in to account facilities available locally.

Understanding the epidemiology of bacterial infections enable in prevention and effective treatment (40). An infectious etiology is only identified in $40-50 \%$ of neutropenic fevers, with $10-30 \%$ having bacteremia $(41,42)$. We continuously investigated incidence of infections in the LHBCC to understand the changing spectrum of organisms and their antibiotic sensitivity. We had bacteraemia only in 4 out of 89 cultures performed during the study period (4\%). It has been reported that positive microbiological detection can vary considerably depending whether they are on antibiotic prophylaxis or not (43). As reported by Klastersky $\mathrm{J}$ et al., in a trail in patients with haematological malignancies, $17 \%$ in the group given prophylaxis compared to $31 \%$ the group with no prophylaxis had positive microbiological detection. The incidence of culture positive episodes of sepsis among our patients are lower than reported elsewhere. However as authors highlighted in the study by Carvalho $A$ et al, variability in reporting of rates makes comparison difficult and there is a need for reporting standardization (44).

The success we encountered may reflect staff and patient awareness and commitment. Clear guidelines, improved communication and strong leadership are necessary to prevent early deaths. Having a resident clinical haematologist experienced in managing neutropenic sepsis, system for rapid clinical evaluation, facilities for intravenous administration of antibiotics, close monitoring of patients for medical complications may have contributed in the lowering mortality.

This is a limited study and further studies are needed over a longer period prior to reaching more definitive conclusions. In addition, we understand the importance of continuously assessing the risks and benefits of the practice and deviations from guidelines from the Western world. Furthermore, we may have to use single agent piperacillin tazobactam and also rotate it with cefepime to reduce emergence of resistance to aminoglycosides as reported by others (45).

\section{Conclusion}

This is the only documented study relating to outcome and successful applicability of western supportive care protocols to Sri Lankan patients with neutropenia. In this study we have shown that survival data comparable to developed countries can be achieved in the setting of limited resources with service 
development, following guidelines and staff training. This is a limited pilot study and we believe this published data will help in further development of the speciality of blood cancer care in the local setting.

\section{Declarations}

Acknowledgements

We acknowledge all patients, management and health care workers at Lanka Hospital, Colombo, Sri Lanka.

Funding: No external funding was sought for the study.

Conflicts of interest/Competing interests: No conflicts of interest.

Availability of data and material: Data used for the study is available from the corresponding author.

Code availability: The data that support the findings of this study are available on request from the corresponding author.

Ethics approval: Approval was obtained from the Lanka Hospitals medical and research committee.

Consent to participate: Consent for data storage and analysis obtained from patients at the time of review.

Consent for publication: Consent for publication of anonymised data was obtained from patients at the time of treatment.

Author Contributions

SH: contributed to the conception, design, acquisition and analysis of data, writing, review and editing, provided health care to patients. TS: contributed to acquisition of data, writing, review and editing, provided health care to patients. CJ: contributed to the conception, design, acquisition and analysis of data, writing, review and editing. SD, DS, DG, NP, EP, MH, SS, NM, SH, GA, RW, GG: contributed to acquisition of data, writing, review and editing, provided health care to patients. JB contributed to the conception, design, acquisition and analysis of data, writing, review and editing, provided health care to patients. All co-authors reviewed manuscript and agreed about the contents.

\section{References}

1. Williams MD, Braun LA, Cooper LM et al (2004) Hospitalized cancer patients with severe sepsis: analysis of incidence, mortality, and associated costs of care. Crit Care 8:R291-R298. https://doi.org/10.1186/cc2893

Page 10/22 
2. Chang H, Rodriguez V et al (1976) Cause of death in adults with acute leukaemia. Medicine 55:259268

3. Ornelas-Sánchez M, Nuño-Vázquez L, Loera-Reyna A et al (2018) The "Golden Hour": a capacitybuilding initiative to decrease life-threating complications related to neutropenic fever in patients with hematologic malignancies in low- and middle-income countries. Blood Adv 2:63-66. https://doi.org/10.1182/bloodadvances.2018GS112240

4. Hewamana S, Kandabadage L, Skandarajah T et al (2021) Applicability of Western protocols in resource-limited setting: Real-world data of long-term outcome of intensive treatment of adult acute myeloid leukaemia in Sri Lanka. eJHaem jha2.191. https://doi.org/10.1002/jha2.191

5. Hewamana S, Kandabadage L, Skandarajah T et al (2021) Applicability of protocols from highincome countries in a resource limited setting; real world data of histopathology, clinical features and long-term outcome of Hodgkin Lymphoma in Sri Lanka. eclinm-D-21-00161R4(Ref. No.: eclinm-D-2100161R4; accepted on 12.06.2021)

6. Zimmer AJ, Freifeld AG (2019) Optimal Management of Neutropenic Fever in Patients with Cancer. J Oncol Pract 15:19-24. https://doi.org/10.1200/JOP.18.00269

7. Gibson C, Berliner N (2014) How we evaluate and treat neutropenia in adults. Blood 124:1251-1258. https://doi.org/10.1182/blood-2014-02-482612

8. Schelenz S, Nwaka D, Hunter PR (2013) Longitudinal surveillance of bacteraemia in haematology and oncology patients at a UK cancer centre and the impact of ciprofloxacin use on antimicrobial resistance. J Antimicrob Chemother 68:1431-1438. https://doi.org/10.1093/jac/dkt002

9. Lyman GH, Kuderer NM, Crawford J et al (2011) Predicting individual risk of neutropenic complications in patients receiving cancer chemotherapy. Cancer 117:1917-1927. https://doi.org/10.1002/cncr.25691

10. Caggiano V, Weiss RV, Rickert TS, Linde-Zwirble WT (2005) Incidence, cost, and mortality of neutropenia hospitalization associated with chemotherapy. Cancer 103:1916-1924. https://doi.org/10.1002/cncr.20983

11. Julius JM, Hammerstrom A, Wei C et al (2017) Defining the impact of the use of granulocyte colony stimulating factors on the incidence of chemotherapy-induced neutropenia in patients with gynecologic malignancies. J Oncol Pharm Pract 23:121-127. https://doi.org/10.1177/1078155215623084

12. Lyman GH, Kuderer NM, Djulbegovic B (2002) Prophylactic granulocyte colony-stimulating factor in patients receiving dose-intensive cancer chemotherapy: a meta-analysis. Am J Med 112:406-411. https://doi.org/10.1016/s0002-9343(02)01036-7

13. Nesher L, Rolston KVI (2014) The current spectrum of infection in cancer patients with chemotherapy related neutropenia. Infection 42:5-13. https://doi.org/10.1007/s15010-013-0525-9

14. Weycker D, Barron R, Kartashov A et al (2014) Incidence, treatment, and consequences of chemotherapy-induced febrile neutropenia in the inpatient and outpatient settings. J Oncol Pharm Pract 20:190-198. https://doi.org/10.1177/1078155213492450 
15. Klastersky J, de Naurois J, Rolston K et al (2016) Management of febrile neutropaenia: ESMO Clinical Practice Guidelines. Ann Oncol 27:v111-v118. https://doi.org/10.1093/annonc/mdw325

16. Ha YE, Song J-H, Kang WK et al (2011) Clinical factors predicting bacteremia in low-risk febrile neutropenia after anti-cancer chemotherapy. Support Care Cancer 19:1761-1767. https://doi.org/10.1007/s00520-010-1017-4

17. Klastersky J, Paesmans M, Rubenstein EB et al (2000) The Multinational Association for Supportive Care in Cancer risk index: A multinational scoring system for identifying low-risk febrile neutropenic cancer patients. J Clin Oncol 18:3038-3051. https://doi.org/10.1200/JC0.2000.18.16.3038

18. Ammann RA, Hirt A, Lüthy AR, Aebi C (2003) Identification of children presenting with fever in chemotherapy-induced neutropenia at low risk for severe bacterial infection. Med Pediatr Oncol 41:436-443. https://doi.org/10.1002/mpo.10320

19. Kuderer NM, Dale DC, Crawford J et al (2006) Mortality, morbidity, and cost associated with febrile neutropenia in adult cancer patients. Cancer 106:2258-2266. https://doi.org/10.1002/cncr.21847

20. Weycker D, Malin J, Edelsberg J et al (2008) Cost of neutropenic complications of chemotherapy. Ann Oncol 19:454-460. https://doi.org/10.1093/annonc/mdm525

21. Klastersky J, de Naurois J, Rolston K et al (2016) Management of febrile neutropaenia: ESMO Clinical Practice Guidelines. Ann Oncol 27:v111-v118. https://doi.org/10.1093/annonc/mdw325

22. Gafter-Gvili A, Fraser A, Paul M et al (2012) Antibiotic prophylaxis for bacterial infections in afebrile neutropenic patients following chemotherapy. Cochrane Database of Systematic Reviews. https://doi.org/10.1002/14651858.CD004386.pub3

23. Smith TJ, Bohlke K, Lyman GH et al (2015) Recommendations for the Use of WBC Growth Factors: American Society of Clinical Oncology Clinical Practice Guideline Update. J Clin Oncol 33:31993212. https://doi.org/10.1200/JC0.2015.62.3488

24. Schelenz S, Nwaka D, Hunter PR (2013) Longitudinal surveillance of bacteraemia in haematology and oncology patients at a UK cancer centre and the impact of ciprofloxacin use on antimicrobial resistance. J Antimicrob Chemother 68:1431-1438. https://doi.org/10.1093/jac/dkt002

25. Nucci M, Biasoli I, Akiti T et al (2000) A double-blind, randomized, placebo-controlled trial of itraconazole capsules as antifungal prophylaxis for neutropenic patients. Clin Infect Dis 30:300305. https://doi.org/10.1086/313654

26. Edelsberg J, Weycker D, Bensink M et al (2020) Prophylaxis of febrile neutropenia with colonystimulating factors: the first 25 years. Curr Med Res Opin 36:483-495. https://doi.org/10.1080/03007995.2019.1703665

27. McNeil C (2005) NCCN guidelines advocate wider use of colony-stimulating factor. J Natl Cancer Inst 97:710-711. https://doi.org/10.1093/jnci/97.10.710

28. Casewell M, Phillips I (1978) Food as a source of Klebsiella species for colonisation and infection of intensive care patients. J Clin Pathol 31:845-849. https://doi.org/10.1136/jcp.31.9.845

29. Wright C, Kominos SD, Yee RB (1976) Enterobacteriaceae and Pseudomonas aeruginosa Recovered from Vegetable Salads. Appl Environ Microbiol 31:453-454. https://doi.org/10.1128/AEM.31.3.453- 


\subsection{6}

30. Gardner A, Mattiuzzi G, Faderl S et al (2008) Randomized comparison of cooked and noncooked diets in patients undergoing remission induction therapy for acute myeloid leukemia. J Clin Oncol 26:5684-5688. https://doi.org/10.1200/JC0.2008.16.4681

31. Ramphal R, Gucalp R, Rotstein C et al (1996) Clinical experience with single agent and combination regimens in the management of infection in the febrile neutropenic patient. The American Journal of Medicine 100:83S-89S. https://doi.org/10.1016/S0002-9343(96)00113-1

32. Guarana M, Nucci M, Nouér SA (2019) Shock and Early Death in Hematologic Patients with Febrile Neutropenia. Antimicrob Agents Chemother 63:. https://doi.org/10.1128/AAC.01250-19

33. Herbst C, Naumann F, Kruse E-B et al (2009) Prophylactic antibiotics or G-CSF for the prevention of infections and improvement of survival in cancer patients undergoing chemotherapy. Cochrane Database Syst Rev CD007107. https://doi.org/10.1002/14651858.CD007107.pub2

34. Hann I, Viscoli C, Paesmans M et al (1997) A comparison of outcome from febrile neutropenic episodes in children compared with adults: results from four EORTC studies. International Antimicrobial Therapy Cooperative Group (IATCG) of the European Organization for Research and Treatment of Cancer (EORTC). Br J Haematol 99:580-588. https://doi.org/10.1046/j.13652141.1997.4453255.x

35. Ghosh S, Chakraborty M, Samanta S et al (2021) Analysis of blood stream infections, antibiograms and clinical outcomes in haematological patients with febrile neutropenia: data from a tertiary care haematology institute in India. Ann Hematol 100:395-403. https://doi.org/10.1007/s00277-02004324-8

36. Rosa RG, Goldani LZ (2014) Cohort study of the impact of time to antibiotic administration on mortality in patients with febrile neutropenia. Antimicrob Agents Chemother 58:3799-3803. https://doi.org/10.1128/AAC.02561-14

37. Ali N, Baqir M, Hamid A, Khurshid M (2015) Febrile neutropenia: median door-to-needle time - results of an initial audit. Hematology 20:26-30. https://doi.org/10.1179/1607845414Y.0000000169

38. Aguilar-Guisado M, Espigado I, Martín-Peña A et al (2017) Optimisation of empirical antimicrobial therapy in patients with haematological malignancies and febrile neutropenia (How Long study): an open-label, randomised, controlled phase 4 trial. Lancet Haematol 4:e573-e583. https://doi.org/10.1016/S2352-3026(17)30211-9

39. Innes HE, Smith DB, O'Reilly SM et al (2003) Oral antibiotics with early hospital discharge compared with in-patient intravenous antibiotics for low-risk febrile neutropenia in patients with cancer: a prospective randomised controlled single centre study. $\mathrm{Br} \mathrm{J}$ Cancer 89:43-49. https://doi.org/10.1038/sj.bjc.6600993

40. Carvalho AS, Lagana D, Catford J et al (2020) Bloodstream infections in neutropenic patients with haematological malignancies. Infect Dis Health 25:22-29. https://doi.org/10.1016/j.idh.2019.08.006 
41. Nesher L, Rolston KVI (2014) The current spectrum of infection in cancer patients with chemotherapy related neutropenia. Infection 42:5-13. https://doi.org/10.1007/s15010-013-0525-9

42. Crawford J, Dale DC, Lyman GH (2004) Chemotherapy-induced neutropenia: risks, consequences, and new directions for its management. Cancer 100:228-237. https://doi.org/10.1002/cncr.11882

43. Klastersky J, de Naurois J, Rolston K et al (2016) Management of febrile neutropaenia: ESMO Clinical Practice Guidelines. Ann Oncol 27:v111-v118. https://doi.org/10.1093/annonc/mdw325

44. Carvalho AS, Lagana D, Catford J et al (2020) Bloodstream infections in neutropenic patients with haematological malignancies. Infect Dis Health 25:22-29. https://doi.org/10.1016/j.idh.2019.08.006

45. Hashino S, Morita L, Kanamori $\mathrm{H}$ et al (2012) Clinical impact of cycling the administration of antibiotics for febrile neutropenia in Japanese patients with hematological malignancy. Eur $\mathrm{J}$ Clin Microbiol Infect Dis 31:173-178. https://doi.org/10.1007/s10096-011-1290-2

\section{Tables}

Table $1 \mathrm{~A}$

Cause of neutropenia and mode of management of neutropenic episodes during the study period.

\begin{tabular}{|lllll|}
\hline & & Post - chemotherapy & Disease - related & Total \\
\hline Managed as in-patient & Sepsis & 43 & 9 & 52 \\
& No sepsis & 12 & 20 & 32 \\
\hline Managed in the community & & & & \\
& (No sepsis) & 60 & 25 & 85 \\
\hline & Total & 115 & 54 & 169 \\
\hline
\end{tabular}

\section{Table 1B}

Age, time from chemotherapy to neutropenia in days (CTN); time from neutropenia to sepsis (NTS); Creactive protein $(\mathrm{CRP})$; minimum neutrophil count $(\mathrm{N})$; minimum platelet count $(\mathrm{P})$; minimum haemoglobin $(\mathrm{H})$; time to antibiotics from admission or from onset of sepsis (TTA); duration of antibiotics(A); duration of CSF(G); in-patient stay(IP); duration of neutropenia (DN) in chemotherapy induced and disease induced neutropenia. 


\begin{tabular}{|c|c|c|c|c|c|}
\hline & & $\begin{array}{l}\text { Chemotherapy induced } \\
\text { neutropenia }\end{array}$ & \multicolumn{3}{|c|}{$\begin{array}{l}\text { Disease } \\
\text { induced } \\
\text { neutropenia }\end{array}$} \\
\hline & & Sepsis & No sepsis & Sepsis & No sepsis \\
\hline $\begin{array}{l}\text { Age } \\
\text { (SD) }\end{array}$ & Mean & $50.40(19.25)$ & $\begin{array}{l}48.56 \\
(19.83)\end{array}$ & $64.33(7.57)$ & $60.13(7.84)$ \\
\hline \multirow[t]{3}{*}{ (IQR) } & Median & $56.00(36.00)$ & $\begin{array}{l}53.00 \\
(37.00)\end{array}$ & $\begin{array}{l}58.00 \\
(15.00)\end{array}$ & $58.00(0.00)$ \\
\hline & p-values & CIN p-value $=0.4958$ & & \multicolumn{2}{|c|}{ DIN p-value $=0.1381$} \\
\hline & & Sepsis $p$-value $=0.0416$ & \multicolumn{3}{|c|}{ No Sepsis $p$-value = 0.0136} \\
\hline $\begin{array}{l}\text { CTN } \\
\text { (SD) }\end{array}$ & Mean & $9.349(5.150)$ & $\begin{array}{l}8.542 \\
(3.730)\end{array}$ & NA & NA \\
\hline \multirow{2}{*}{ (IQR) } & Median & $9.00(5.00)$ & $8.00(5.00)$ & NA & NA \\
\hline & p-value & CIN p-value $=0.6423$ & & NA & NA \\
\hline $\begin{array}{l}\text { NTS } \\
\text { (SD) }\end{array}$ & Mean & $1.465(1.120)$ & NA & NA & NA \\
\hline \multirow{2}{*}{ (IQR) } & Median & $1.00(0.00)$ & NA & NA & NA \\
\hline & $p$-value & NA & NA & NA & NA \\
\hline CRP & Mean (SD & $84.1(98.5)$ & NA & $80.0(92.4)$ & NA \\
\hline \multirow{2}{*}{ (IQR) } & Median & $47.6(81.4)$ & NA & $44.7(133.1)$ & NA \\
\hline & $p$-value & Sepsis $p$-value $=0.8337$ & & & \\
\hline $\begin{array}{l}N \\
(S D)\end{array}$ & Mean & $0.2430(0.3280)$ & $\begin{array}{l}0.6282 \\
(0.2981)\end{array}$ & $\begin{array}{l}0.452 \\
(0.336)\end{array}$ & $\begin{array}{l}0.5069 \\
(0.3600)\end{array}$ \\
\hline \multirow[t]{3}{*}{ (IQR) } & Median & $0.0600(0.4600)$ & $\begin{array}{l}0.6950 \\
(0.5275)\end{array}$ & $\begin{array}{l}0.360 \\
(0.665)\end{array}$ & $\begin{array}{l}0.5000 \\
(0.5550)\end{array}$ \\
\hline & p-values & CIN p-value $=0.000$ & & \multicolumn{2}{|c|}{ DIN p-value $=0.6176$} \\
\hline & & Sepsis $p$-value $=0.0185$ & No Sepsis $\mathrm{p}$ & ue $=0.0231$ & \\
\hline
\end{tabular}




\begin{tabular}{|c|c|c|c|c|c|}
\hline$P$ & Mean (SD) & $169.3(134.9)$ & $\begin{array}{l}186.6 \\
(127.6)\end{array}$ & $\begin{array}{l}27.00 \\
(26.66)\end{array}$ & $48.0(78.9)$ \\
\hline \multirow[t]{3}{*}{$(\mathrm{IQR})$} & Median & $139.0(117.0)$ & $\begin{array}{l}183.0 \\
(132.0)\end{array}$ & $\begin{array}{l}16.00 \\
(17.00)\end{array}$ & $20.0(24.0)$ \\
\hline & p-values & CIN p-value $=0.2259$ & & \multicolumn{2}{|c|}{ DIN p-value $=0.4786$} \\
\hline & & Sepsis $p$-value $=0.0003$ & \multicolumn{3}{|c|}{ No Sepsis $p$-value $=0.0000$} \\
\hline $\mathrm{H}$ & Mean (SD) & $9.435(1.816)$ & $\begin{array}{l}10.100 \\
(2.079)\end{array}$ & $\begin{array}{l}7.989 \\
(0.858)\end{array}$ & $\begin{array}{l}8.618 \\
(1.843)\end{array}$ \\
\hline \multirow[t]{2}{*}{$(\mathrm{IQR})$} & Median & $9.000(2.300)$ & $\begin{array}{l}9.850 \\
(2.850)\end{array}$ & $\begin{array}{l}8.000 \\
(1.400)\end{array}$ & $\begin{array}{l}8.800 \\
(1.750)\end{array}$ \\
\hline & p-values & CIN p-value $=0.0582$ & & \multicolumn{2}{|c|}{ DIN p-value $=0.0834$} \\
\hline
\end{tabular}

Sepsis $p$-value $=0.0171$ No Sepsis $p$-value $=0.0002$

$\begin{array}{llllll}\begin{array}{l}\text { TTA } \\ (\mathrm{SD})\end{array} & \text { Mean } & 28.84(14.91) & \text { NA } & \begin{array}{l}37.78 \\ (25.870)\end{array} & \text { NA } \\ & \text { Median } & 20.00(20.00) & \text { NA } & \begin{array}{l}20.00 \\ (40.00)\end{array} & \text { NA } \\ (\text { IQR }) & & & & & \end{array}$

P-value $\quad$ Sepsis $p$-value $=0.4844$

$\begin{array}{llllll}\text { A } & \text { Mean (SD) } & 5.907(4.303) & \text { NA } & 5.22(5.45) & \text { NA } \\ (\text { IQR }) & \text { Median } & 4.000(3.000) & \text { NA } & 3.00(5.5) & \text { NA }\end{array}$

P-value $\quad$ Sepsis $p$-value $=0.0787$

$\begin{array}{lllll}\text { G Mean (SD) } & 4.000(2.517) & \text { NA } & 2.860 & \text { NA } \\ & & & (3.180) & \\ \text { Median (IQR) } & 3.000(4.000) & \text { NA } & 1.000 & \text { NA }\end{array}$

P-value $\quad$ Sepsis $\mathrm{p}$-value $=0.0470$

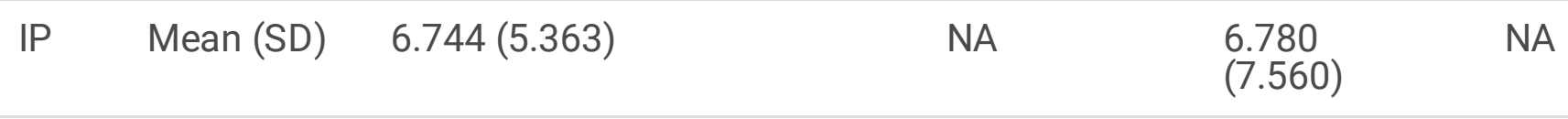

$\begin{array}{llll}\text { Median } & 5.000(4.000) & \text { NA } & 3.000\end{array}$


P-value $\quad$ Sepsis p-value $=0.2828$

$\begin{array}{llllll}\text { DN } & \text { Mean (SD) } & 4.0703 .043 & 4.3755 .226 & \text { NA } & \text { NA } \\ \text { (IQR) } & \text { Median } & 3.000(4.000) & 2.500 & \text { NA } & \text { NA }\end{array}$

P-value $\quad$ CIN p-value $=0.3552$

Table 1C

Time to antibiotic (TTA) during the week days, night and during week-ends.

\begin{tabular}{|ccccc|}
\hline & 7am-7pm M-F & 7pm-7am M-F & 7am-7pm S-S & 7pm-7am S-S \\
\hline Mean (SD) & $28.06(14.26)$ & $30.45(16.04)$ & $30.00(17.61)$ & $23.33(5.77)$ \\
\hline Median (IQR) & $20.00(20.00)$ & $25.00(10.00)$ & $20.00(25.00)$ & $20.00(10.00)$ \\
\hline p-value & Kruskall Wallis p-value $=0.7870$ & \\
\hline
\end{tabular}

Table 2A

Number of culture positive episodes and source of infection during the study period.

\begin{tabular}{|llll|}
\hline & Neutropenic Sepsis & Non-neutropenic Sepsis & Total \\
\hline Blood & 2 & 2 & 4 \\
\hline Urine & 4 & 2 & 6 \\
\hline Sputum & 1 & 2 & 3 \\
\hline Other & 1 & & 1 \\
\hline
\end{tabular}

Table 2B

Source, organism and antibiotic sensitivity of culture positive episodes during the study period.

\section{Figures}




\begin{tabular}{|c|c|c|}
\hline Source & Organism & Antibiotic sensitivity \\
\hline Blood & Klebsiella pneumoniae & Amikacin, Meropenem, Pip+taz, Vanco, Teicoplanin \\
\hline Blood & $\begin{array}{l}\text { Pseudomonas } \\
\text { aeruginosa }\end{array}$ & Amikacin, Meropenem, Pip+taz \\
\hline Blood & Candida species & Amphotericin B, Fluconazole, Itraconazole \\
\hline \multirow[t]{2}{*}{ Blood } & Enterococcus species & Linezolid, Vancomycin, Teicoplanin \\
\hline & Candida species & Amphotericin B, Fluconazole, Itraconazole \\
\hline Urine & Candida species & Fluconazole \\
\hline Urine & Klebsiella pneumoniae & $\begin{array}{l}\text { Gentamycin, Pip+taz, Amikacin, Co-trimoxazole, } \\
\text { Ciprofloxacin }\end{array}$ \\
\hline Urine & $\begin{array}{l}\text { Pseudomonas } \\
\text { aeruginosa }\end{array}$ & Amikacin, Netilmicin, Pip+taz \\
\hline Urine & $\begin{array}{l}\text { Pseudomonas } \\
\text { aeruginosa }\end{array}$ & $\begin{array}{l}\text { Gentamycin, Ceftriaxone, Ciprofloxacin, Amikacin, } \\
\text { Pip+Taz }\end{array}$ \\
\hline Urine & Klebsiella pneumoniae & Gentamycin, Cefotaxime, Ciprofloxacin \\
\hline Sputum & Acinetobacter species & Colistin \\
\hline Sputum & Candida albicans & Fluconazole \\
\hline Sputum & Candida albicans & Fluconazole \\
\hline Sputum & Candida species & Fluconazole \\
\hline \multirow{2}{*}{$\begin{array}{l}\text { Other } \\
\text { (ICD) }\end{array}$} & Staphylococcus & Tetracycline, Clindamycin, Fucidin acid \\
\hline & $\begin{array}{l}\text { Pseudomonas } \\
\text { aeruginosa }\end{array}$ & Mupirocin, Gentamycin, Amikacin, Pip+Taz \\
\hline
\end{tabular}



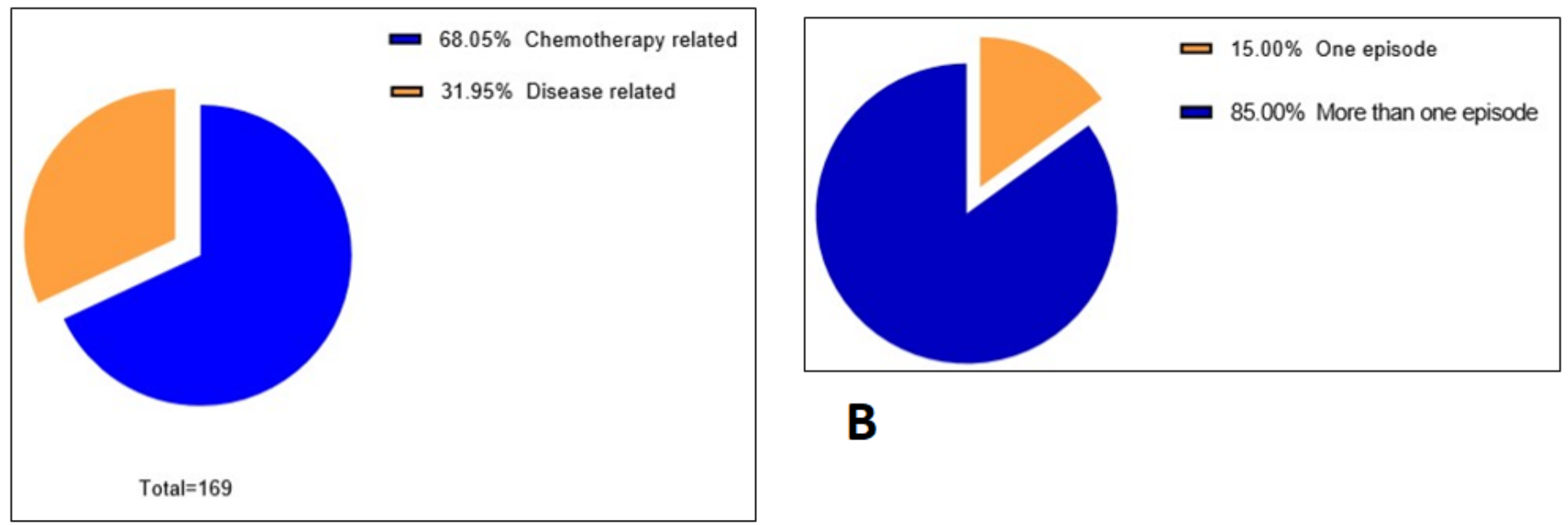

\section{A}

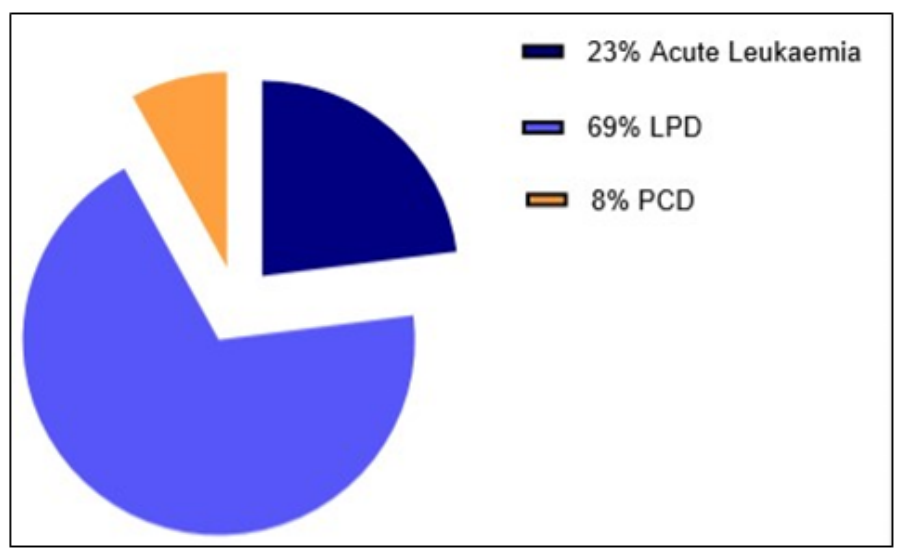

C

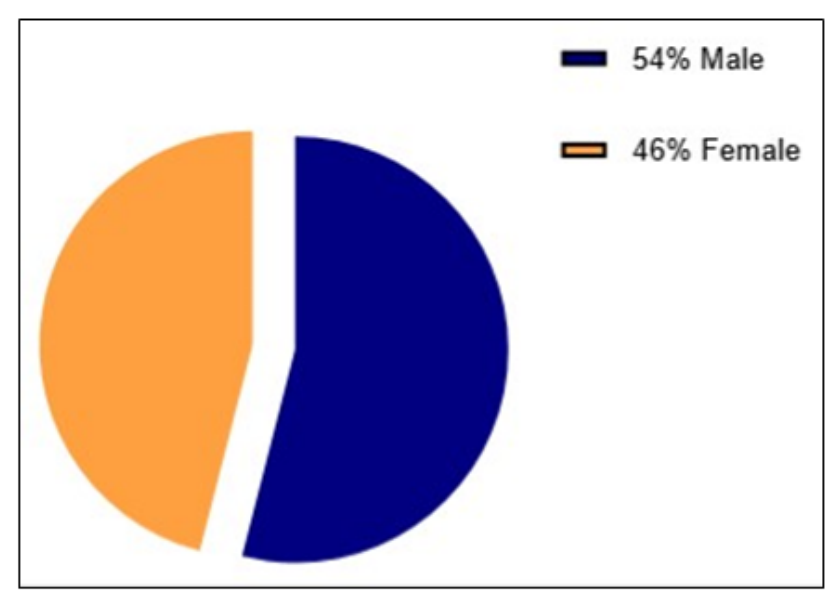

D

\section{Figure 1}

A. Proportion of chemotherapy related neutropenia; B. who had more than one episode of neutropenia C. disease type and D. gender. 

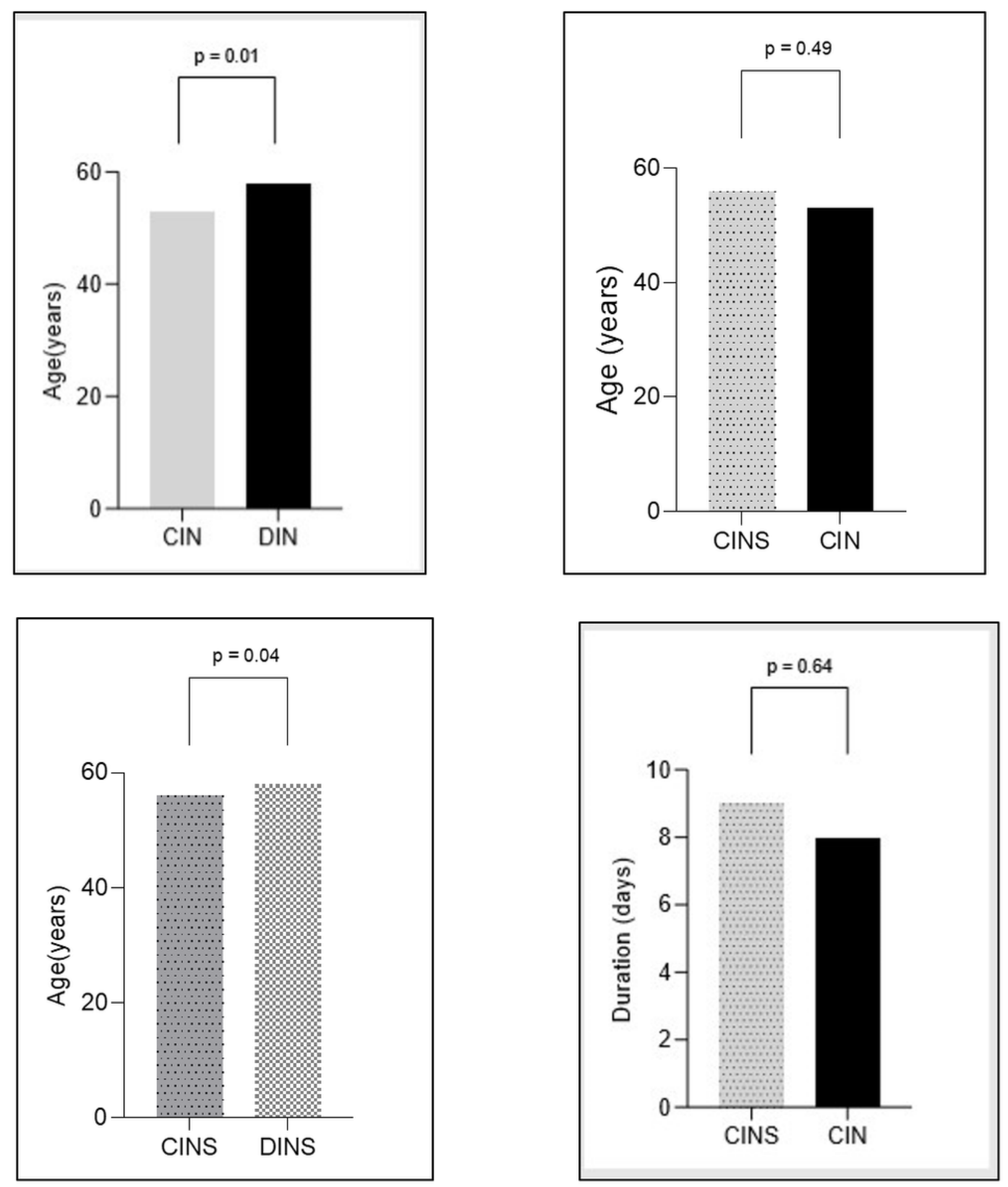

Figure 2

Age distribution in A. chemotherapy induced neutropenic sepsis and no-sepsis; B. in chemotherapy induced and disease induced sepsis; C. chemotherapy induced and disease induced neutropenia and D. duration in days from chemotherapy to neutropenic sepsis and neutropenia. 

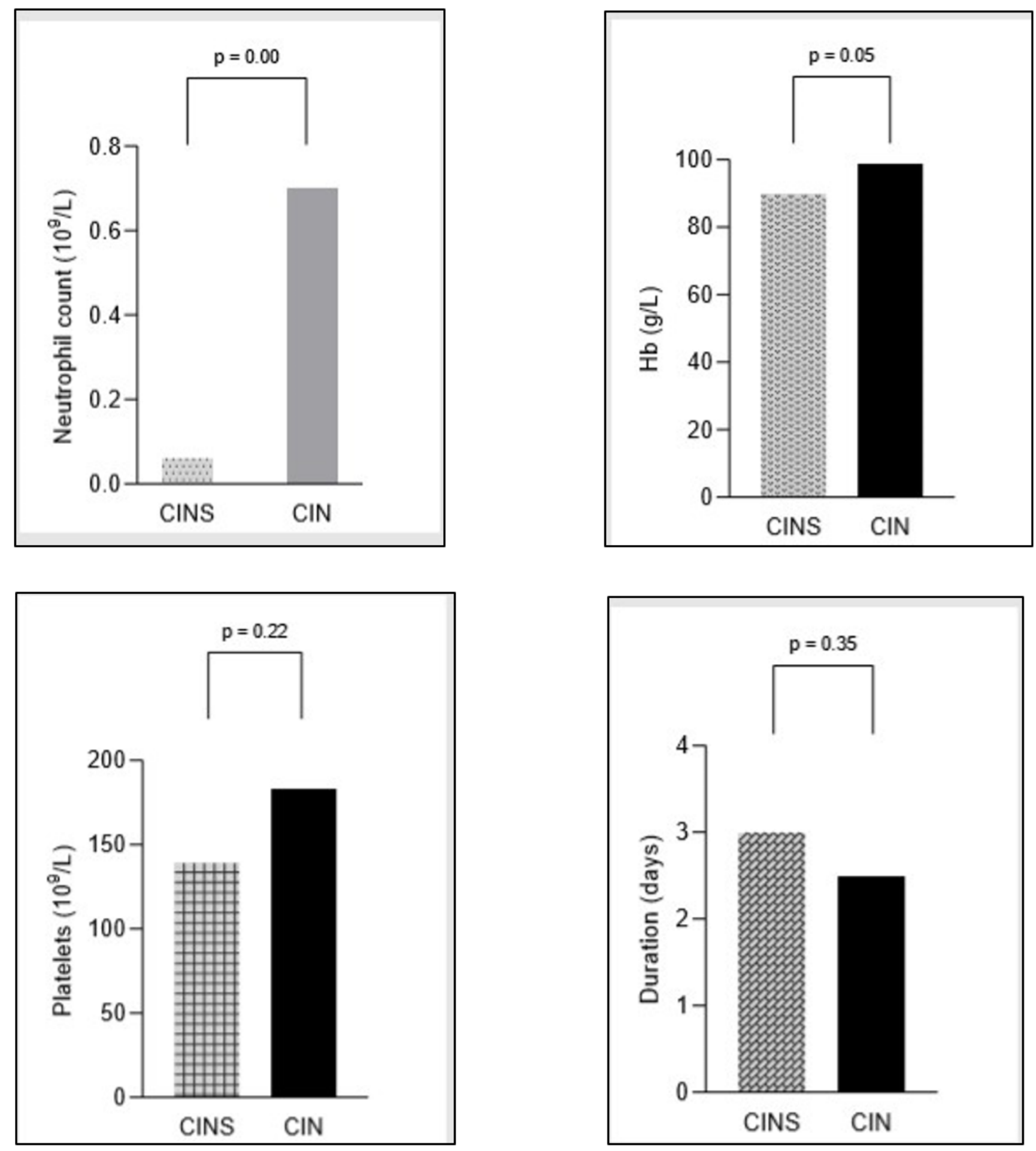

Figure 3

A. neutrophil count; B. haemoglobin; C. platelet count, and D. duration of neutropenia in the chemotherapy induced neutropenic sepsis group compared to non-septic group. 

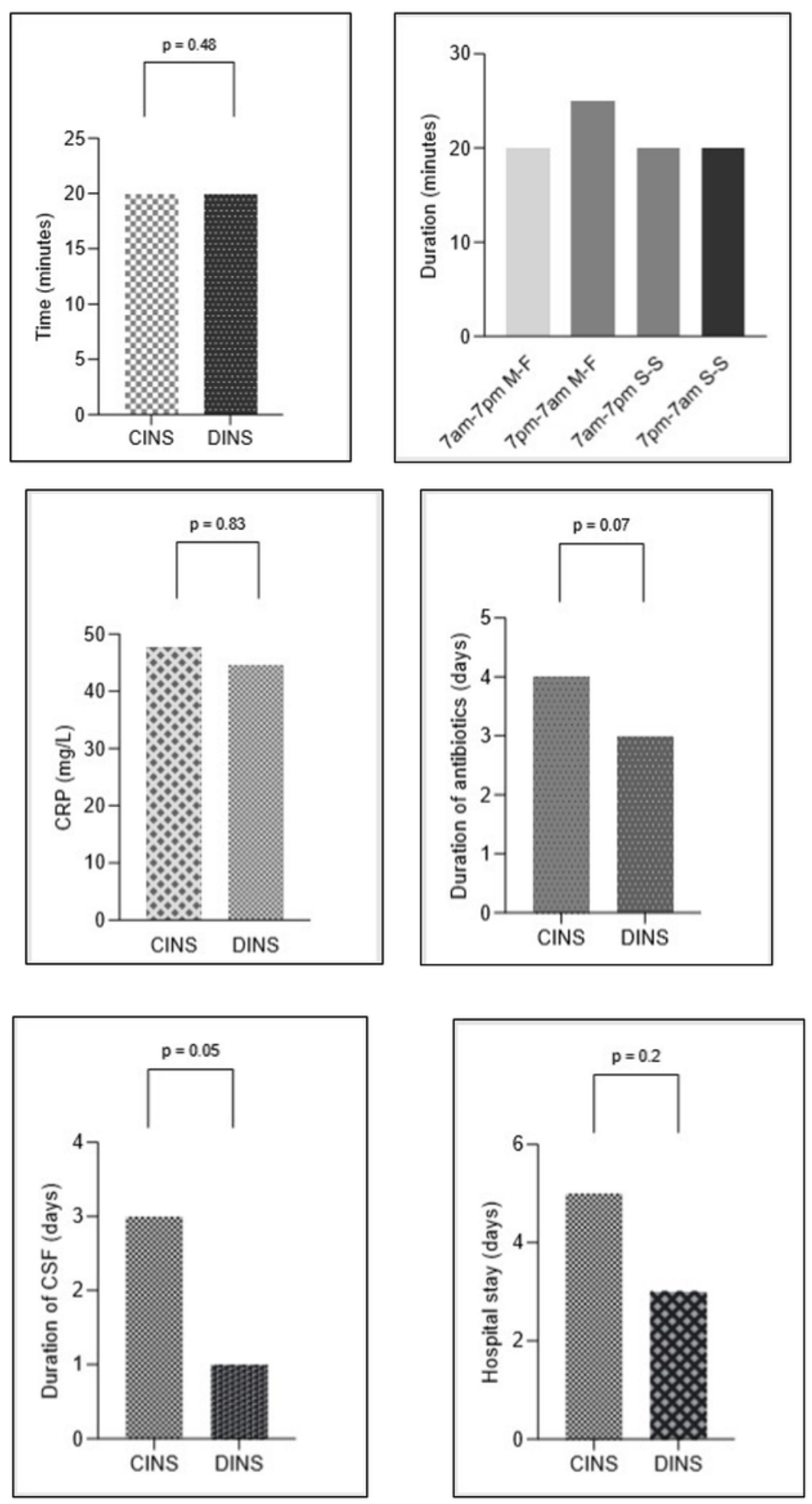

\section{Figure 4}

A. Time to start of antibiotics (TTA); B. Time to start antibiotics during day time, night time and weekends; C. C-reactive protein (CRP); D. duration of antibiotics; E. duration of colony stimulating factors and F. duration of hospital stay in the chemotherapy induced neutropenic sepsis (CINS) group compared to disease induced neutropenic sepsis (DINS) group. 